\title{
Revisitando la historia de las teorías del desarrollo
}

\author{
Revisiting the History of Development Theories
}

RAÚL GONZÁLEZ MEYER

Universidad Academia de Humanismo Cristiano, Chile

RECEPCIÓN: I I/O9/20I2 • ACEPTACIÓN: 4/O6/20I3

RESUMEN El artículo reconstruye el debate en economía del desarrollo desde la Segunda Guerra Mundial hasta hoy. Para ello, lo conecta con el valor del progreso y de la producción de riqueza que ganaron lugar en siglos anteriores. Se revisan los factores que permitieron la emergencia de un discurso desarrollista y, luego, las teorías que surgieron más tarde: el paradigma de la modernización, socialismo industrialista, la Comisión Económica para América Latina (Cepal), dualismo, teoría de la dependencia, aproximaciones sociales, visiones ambientalistas, desarrollo a escala humana, sustitución de importaciones, neoliberalismo, neoestructuralismo, desarrollo étnico, capital humano, desarrollo humano, antidesarrollo y otros. Estas teorías o aproximaciones son vistas desde las inflexiones que marcan respecto a etapas anteriores, así como respecto de las circunstancias históricas que parcialmente explican su emergencia. El artículo concluye proponiendo una posición sobre el estado y el futuro del campo de los estudios de desarrollo en relación con los retos de la sociedad actual. La tesis del artículo es que la referencia teórica y política del desarrollo ha sido y es un concepto controvertido, en disputa e incrustado en la historia.

PALABRAS Clave Progreso, desarrollo, modernización, industrialización, Estado, cultura, estrategias, ecología, liberalismo, socialismo. 
ABSTRACT The article reconstructs the debate on economic development since the Second World War until today. For that, connects to the value of progress and wealth production that won place in previous centuries. It reviews the factors that made the development discourse emerge, and then, the various theories that surfaced later: modernization paradigm, industrialist socialism, the Economic Commission for Latin America (Cepal), dualism, dependency theory, social approaches, environmentalist's visions, human scale development, import substitution, neo-liberalism, neo-structuralism, ethnic development, human capital, human development, anti-development, and others. These theories or approaches are seen in terms of the inflections that marks respect of earlier times, as of historical circumstances that partly explain its occurrence. The article concludes by proposing a position on the state and future of the field of development studies in relation to the challenges of today's society. The thesis of the article is that theoretical and policy reference of the development has been and is a contested concept, embedded in history.

KEYWORDS Progress, development, modernization, industrialization, State, culture, strategies, ecology, liberalism, socialism.

\section{Introducción}

Este artículo reconstruye la trayectoria de las teorías del desarrollo económico, campo especialmente constituido luego de la Segunda Gran Guerra. Sin embargo, muchos de sus contenidos estaban presentes desde períodos anteriores y habían sido parte de la constitución del análisis económico, en lo referido al aumento de la riqueza material, de su distribución y del funcionamiento del sistema económico.

Aun considerando dichos antecedentes históricos, podemos reconocer que cerca de la mitad del siglo XX se despliega un «movimiento desarrollista» específico, teórico y práctico. Dicho movimiento tiene como foco a un grupo de países definidos como «atrasados «, «subdesarrollados» o «no desarrollados» de América Latina, Asia, África Subsahariana y África Árabe. Sin embargo, no se circunscribe a ellos como suele predominantemente afirmarse, sino que abarca también a países más "avanzados», de la Europa del Sur, la Europa del Este y aun, las realidades de los países llamados centrales, en los cuales también se pueden identificar "políticas de desarrollo». Por ejemplo, en Europa 
Occidental, la política de modernización rural, particularmente en Francia, que busca eliminar un sector de agricultura pequeña considerada tradicional, para acercarse a los estándares de productividad norteamericana de la época (Peemans, 2002). Esta universalidad espacial de la cobertura de la teoría y acción desarrollista se acentúa en el tiempo con la aparición de consideraciones que se van a presentar como pertinentes tanto en el Norte como en el Sur. Entre ellas, las relativas a la realidad ecológica, a partir de los años setenta, o los impactos del neoliberalismo y globalización en los años ochenta y noventa.

\section{Progreso, desarrollismo y Estado}

La emergencia del desarrollismo del siglo XX se inscribe dentro de la historia más larga del avance de la idea de progreso en y desde Occidente, entendida como una condición de la humanidad, expresión del despliegue de la razón, y subjetivamente valorada como positiva (Le Goff, 2005). Desde ese lente se pudieron establecer con convicción, desde los países centrales y algunas élites periféricas, dicotomías del tipo civilización-barbarie, razón-irracionalidad, ilustración-ignorancia o ciencia-superstición. ${ }^{1}$ El progreso se concreta e identifica en la ciencia, la tecnología y la producción de riqueza, expresiones empíricas de la capacidad humana de comprensión del mundo físico, y luego social, y de manipularlo u organizarlo para su beneficio (Preston, I999). Aquel trayecto no estuvo falto de escepticismos, problematizaciones o contestaciones en el propio centro donde ocurrió el progreso: los análisis sobre la explotación y alienación del trabajo o su sometimiento al capital (socialismo utópico, Hegel, Marx), los límites al crecimiento y mejoramiento de las condiciones de vida por la contradicción entre crecimiento demográfico y tierras fértiles escasas (Malthus y economistas del siglo XIX), la necesidad de vías propias de industrialización — protegida y con apoyo estatal— en relación al patrón liberal inglés como en la escuela histórica alemana (F. Lizt). A ello se agregan cuestionamientos al progreso occidental provenientes desde realidades más periféricas, por ejemplo, desde la búsqueda de armonizar desarrollos técnicos y grados de modernización con el resguardo de las organizaciones y culturas campesinas,

I. Las empresas colonialistas están sostenidas subjetiva y éticamente en esa idea de civilización superior como expresión de progreso acumulado y en despliegue. Superioridad que estaría en las dimensiones tecnológicas y axiológicas y en que el «contacto» permite transmitir algo bueno para el colonizado. 
en lo que podríamos denominar el intento de una vía comunitario-campesina de modernización, expresados en el «populismo ruso» de la segunda mitad del siglo XIX, también, posteriormente, en el gandhismo y, en algún grado menor, en el maoísmo; asimismo, en las ideas de pensar el desarrollo desde una singularidad espacio temporal en las ideas de Haya de La Torre sobre Indoamérica.

La noción de desarrollo como fundamento y referencia central para la acción política nacional e internacional, luego de la Segunda Guerra Mundial, puede ser imaginada como una «refracción» de aquella ideología y cultura del progreso. Por un lado, es prolongación o reencarnación de éstas. Por otro, representa una variación en términos de una explícita acción para construirlo, a través de dispositivos institucionales, políticos y teóricos, y la elaboración de estrategias. Allí emerge el campo de las "ciencias sociales del desarrollo» (economía, sociología, antropología, ciencia política) que se ordena bajo las preguntas relacionadas de por qué algunos países son desarrollados, qué recorrido han hecho, y qué debe hacerse para que aquellos que no lo son avancen a ese estadio. Ello comprenderá también a países de modernización intermedia y, aun, comprenderá la profundización del avance de los países considerados adelantados, a fin de consolidar una sociedad de alto consumo de masas. Se define, así, un campo de teoría y acción con paradigmas dominantes de valor temporal, y que será también uno de importantes disputas a distintos niveles, incluyendo la puesta en cuestión de la propia noción de desarrollo y de su pertinencia universal.

Varios fenómenos antes y durante la mitad del siglo XX contribuyen a aquella «refracción» antes señalada. En lo histórico, la descolonización de buena parte de Asia y de África del Norte y Subsahariana, donde sus nuevas clases dirigentes y luchadores anticoloniales sustentaron su legitimidad tanto en el principio de la autonomía nacional como en el avance hacia el desarrollo, diagnosticado como negado por la condición colonial. En América Latina, las tendencias hacia proyectos de industrialización nacional producto de los límites del modelo primario exportador, del reforzamiento de la industrialización espontánea resultante de eventos externos — guerras y Gran Depresión- y del surgimiento de nuevos grupos — clases medias, industriales y grupos populares- que pusieron en crisis un tipo de dominación oligárquica heredada del siglo XIX. En Europa, las tareas de reconstrucción de la posguerra, incluyendo el Plan Marshall, que alimentan acciones programadas y estratégicas; pero también los planteamientos de la necesidad de políticas de desarrollo en Europa del Sur, caracterizada con insuficiente modernidad propicia peligro- 
samente el surgimiento de líderes nacionalistas carismáticos; y la emergencia de un bloque nuevo de países socialistas en Europa del Este que se proponen salir de su atraso relativo y desarrollar sus fuerzas productivas a través del «atajo histórico» con que es connotada esa orientación, en comparación a la vía capitalista. Por último, el avance de una lectura de pobreza material como caracterizadora de buena parte del mundo, en contradicción con la visión de una modernidad avanzada en lo científico-tecnológico y que hacía emerger, en élites internacionales, de manera complementaria y contradictoria, por un lado, impulsos éticos a actuar y, por otro, miedo a las inestabilidades políticas futuras por expectativas masivas de bienestar que no fueran satisfechas.

En lo teórico, en conexión con aquellos procesos históricos, varios fenómenos empujan el lugar protagónico del desarrollo como referencia normativa para la acción. El keynesianismo había dado fundamentos sólidos a la acción estatal dentro del capitalismo para enfrentar la amenaza permanente de insuficiente demanda agregada como fuente de ciclos depresivos. Ello se prolongaría luego entre economistas poskeynesianos que en perspectivas de mediano plazo concluían la inexistencia de mecanismos espontáneos del mercado para asegurar trayectorias de crecimiento económico con equilibrio en el tiempo entre el ahorro y la inversión y entre el aumento de la fuerza de trabajo y el aumento de los empleos² (Harrod, I948). Más decisivamente aun, es un período en que gana prestigio la planificación, la que es connotada de un recurso clave para una acción política racional, con una ganancia en tiempo y eficacia para construir el desarrollo y en que la URSS aparece como encarnación y ejemplo exitoso de ello. Aun países no socialistas se sentirán atraídos por la planificación soviética, como la India post-Gandhi, y la mayoría de los países occidentales crearán ministerios de planificación la que, dentro del contexto y lenguaje de la

2. Los poskeynesianos partieron del postulado keynesiano de que en un momento dado la economía podría tener un equilibrio con empleo alto si la magnitud de la inversión era suficiente para ocupar la masa de ahorro generado. Pero se centraron en que dado que esa inversión, como proceso permanente en el tiempo para asegurar aquel equilibrio, significaba un aumento también permanente de la capacidad productiva, necesitaba, a la vez, un crecimiento permanente de la demanda agregada de bienes y servicios que hiciese el proceso sustentable en el tiempo y que, a la vez, dicho ritmo fuera tal, que asegurase la ocupación del natural crecimiento de la fuerza de trabajo, no generando, en el mediano plazo, ya sea un déficit de trabajadores o ya sea un desempleo estructural. 
Guerra Fría, se caracterizará como indicativa y democrática en oposición a la imperativa y autoritaria de los países socialistas. Esto se acompaña del aumento de técnicas que le van dando sustancia, como la matriz insumo-producto, la que relacionaba las producciones de cada sector de la economía con la necesidad de insumos provenientes de los otros sectores y de sí mismo, los que definían los «coeficientes técnicos de producción». Junto con ser un cuadro que representaba en términos estáticos las relaciones intersectoriales de la economía se ofrecía como un gran instrumento de planificación de las necesidades de producción (y de importación) a partir de establecer algunas grandes metas centrales de crecimiento de determinados sectores económicos. Dos autores precursores de esta técnica fueron W. Leontief y Von Neumann en la década de los treinta y cuarenta.

\section{Lectura desde la dicotomía tradición/modernidad: evolucionismo y dualismo}

Una aproximación inicial envolvente de la perspectiva desarrollista la constituye el paradigma de la modernización (García, I986). Éste ordenó el tiempo histórico desde las categorías de sociedad tradicional y sociedad moderna, en donde el subdesarrollo aparece como la expresión económica de aquel primer "estadio», definido como la antítesis de una sociedad moderna cuyas referencias avanzadas eran Estados Unidos y parte de Europa. Lo tradicional quedaba asociado a un estadio retardado sin historia, marcado - al contrario de la situación moderna - por la no acumulación de medios productivos, bajo producto, bajo consumo, baja productividad, falta de motivaciones hacia el progreso y el confort material, y falta de agentes e instituciones generadores de actividad económica en función de una ganancia. Dicho enfoque dotó de una lectura universal del momento histórico — transición de lo tradicional a lo moderno- y al proyecto de modernizarse como el desafío histórico de los países.

Esta condición moderna contenía dimensiones políticas, como la secularización y la existencia de sistemas de partidos y representación; culturales, como la valorización del confort material y el cálculo racional; y económicas, asociadas al crecimiento, a los procesos de ahorro-inversión, que lo hacen posible, y a un proceso incesante de división, especialización y productividad del trabajo y la expansión de los mercados, para lo que la industrialización aparecía como una condición y vía necesaria. Estas tres dimensiones se entendían reforzándose mutuamente, actuando cada una como condición favorable para las otras, 
aunque era finalmente en lo económico donde debía fundamentalmente verificarse el grado de modernización avanzado. Lo cultural, sin embargo, era clave para dotar de las fuerzas motivacionales centrales de la modernización y lo político para presionar y «administrar» el cambio societal sujeto a posibles resistencias y desequilibrios (Almond, I960).

En ese marco se puede inscribir la popular obra de W.W. Rostow y su sistematización en cinco etapas del proceso histórico de modernización económica recorrido por Occidente, llamado a hacer de espejo para mirar el recorrido llevado a cabo y por acometer en cada sociedad nacional. Todo comienza en una sociedad tradicional en los términos antes descritos. Desde esa situación, pasando por sucesivas etapas, se podía llegar a la moderna sociedad de la abundancia con alto consumo de bienes privados y públicos (Rostow, I963). Los cambios primero son lentos y suponen el nacimiento de agentes y fuerzas minoritarias que van difundiendo las prácticas, valores e instituciones modernos hasta hacerlos prevalecer. Ésta es una acumulación en el tiempo pero que tiene saltos y que en su faceta más económica se expresa en el aumento del ahorro y la inversión. La etapa clave es la tercera, la del «despegue» — históricamente asociable a la revolución industrial - en que se impone la inflexión hacia la sociedad económica moderna, aunque pueden existir reversiones o estancamientos. Dentro de la amplia acumulación de factores que van produciendo esa dirección y momento, algunos juegan un rol particularmente importante: la existencia de una masa mínima crítica de «hombres de empresa» capaces de usar productivamente el capital económico acumulado; la existencia de una institucionalidad que permita que el excedente potencial de la economía sea mayoritariamente transferido y usado por dichos agentes inversores; la existencia de sectores productivos líderes, como lo fue la industria textil en Inglaterra o el ferrocarril en otros países, que abren enormes oportunidades de inversión y arrastran a través de enlaces a una buena parte del resto de la economía.

Algo importante en la lectura de Rostow es que la llegada al bienestar masivo y de alto consumo, etapa de la abundancia de bienes y servicios, requiere de una fase previa que prosigue a la del despegue y que es un período de acumulación de fuerzas productivas. Aun así, su visión termina siendo una representación histórica poco conflictual de los procesos de modernización que hace un tanto invisibles los dolores de la acumulación originaria, la expropiación de los campesinos y la explotación de los obreros, como lo había descrito Marx, el siglo anterior.

En ese mismo marco de análisis, aunque con una focalización más precisa 
en la realidad de los países pobres, podemos ubicar el enfoque dualista. Para éste, en su versión más clásica, aquellos están constituidos por dos economías separadas, una tradicional agrícola-rural y otra moderna (capitalista) industrial-urbana (Lewis, I 964). ${ }^{3}$ La primera, caracterizada en los términos convencionales - baja productividad, bajo producto, bajo consumo, sin inversiónes además descrita con una enorme masa de población que tenía productividad cero o muy baja, menor a lo que consumía para sobrevivir. Este «excedente estructural de mano de obra» en el sector rural, si dejaba de estar en el campo no producía disminución de la producción agrícola. Desde esa premisa, el dualismo planteaba que el desafío central para el desarrollo era el traslado de esa masa excedentaria hacia el sector capitalista moderno - convirtiéndola en proletariado industrial - definido con productividad alta y en donde existía una masa de utilidades constantemente reinvertidas. Ello suponía algún salario diferencial positivo en la industria que atrajese migrantes, pero que en la medida que fuese una oferta importante permitiría mantener el nivel de salarios urbanos dentro de márgenes acotados que no pusieran en cuestión la acumulación moderna, hasta que fuese absorbida toda la masa excedentaria, momento que definía una sociedad y economía unificadas (Lewis, 1964).

Sin embargo, dentro de este marco, autores dualistas plantearon que este proceso podía ofrecer problemas, los que resultaron ser de gran actualidad y significado para muchos países «en transición» (Ranis, 1993). Uno era que si la mayoría de los migrantes algún grado de aporte hacían a la actividad agrícola, aunque fuese con productividad baja — como parecía ser la realidad de las economías agrarias-, dicha migración disminuía la producción de alimentos encareciendo sus precios y dificultando la reproducción básica de los trabajadores urbanos y/o bajando la tasa de ganancia en el sector moderno por la necesidad de aumentar los salarios. Ello llevaba a enfatizar algo que se hizo clave en los debates sobre desarrollo: la necesidad de la modernización agrícola como condición para la industrial y para el éxito de la modernización en general. El otro era la posibilidad que la migración campo-ciudad fuera a un ritmo por sobre la oferta de empleo generada por el sector moderno, lo que

3. Sin embargo, en su versión original la noción de dualismo fue usada en un estudio sobre Indonesia en que el economista holandés Boecke distinguía dos economías paralelas dentro del sector agrícola: la economía campesina de autosubsistencia (tradicional) y una economía comercial de exportación (moderna) (Kanbur y McIntosch, I993). 
llevaría a un desempleo urbano, a la manera de un "excedente estructural de mano de obra», pero ahora en la ciudad. Para enfrentar esto era necesario asegurar una composición del crecimiento que le diera importancia a los sectores productivos creadores de empleo y a un ritmo de modernización tecnológica que no provocara un desmedido ahorro de mano de obra. ${ }^{4}$ Algunos autores cono G. Ranis y J. Fei plantearán que estos dos problema habían sido muy bien resueltos por la estrategia de modernización seguida por Japón durante el siglo XX levantando, de paso, a este proceso como una referencia de modernización exitosa distinta a la occidental (Ranis, I993).

\section{Círculos viciosos y otros diagnósticos orientadores de la acción desarrollista del Estado}

Estos primeros tiempos de análisis enmarcado en el imperativo del desarrollo hicieron emerger diagnósticos y proposiciones más puntuales y específicos que, aunque no alcanzaron el carácter de «teorías del desarrollo», configuraron un núcleo de representaciones acerca de los países subdesarrollados. Asimismo, tuvieron el importante significado de fundar y orientar lo que debía ser la «necesaria» o "correcta» acción desarrollista del Estado.

Un tipo de representaciones es la de los «círculos viciosos», la que puede tomar varias formas cercanas entre sí. Por ejemplo, países pobres con pocos ingresos generan poco ahorro, lo que determina una inversión baja, esto define un crecimiento muy pequeño del producto y del ingreso, con lo que el ahorro y la inversión continuarán siendo bajos, reproduciéndose el ciclo señalado. Ello puede alcanzar formulaciones radicales como las de Leibenstein acerca de países pobres con trabajadores mal alimentados, productividad baja y pobreza que se reproduce (Leibenstein, I957). En definitiva, se es pobre porque se es pobre (Nurkse, I973). También se populariza en la época la visión de las economías subdesarrolladas como extravertidas y fragmentadas, es decir, con un sector moderno orientado hacia el exterior y carente de articulaciones internas — tipo enclave- lo que impedía la difusión del progreso técnico en su interior.

4. La cuestión del ritmo de creación de empleo urbano reaparecería con fuerza en la discusión a mediados de los años setenta en torno a la noción de sector informal urbano que constituiría en su momento la base de un diagnostico de los problemas de la industrialización del «tercer mundo» en cuanto incapaz de generar suficientes puestos de trabajo. 
Eso era contrapuesto a las economías avanzadas que eran caracterizadas como intravertidas y con fuertes articulaciones internas, conformando un espacio económico nacional denso (Perroux, 1958).

Algo importante es que esos diagnósticos fundaban la necesidad de políticas que ya sea rompiesen círculos viciosos o generasen articulaciones internas. Los agentes privados y los incentivos de mercado si bien no eran rechazados por buena parte de los teóricos desarrollistas, particularmente los «no socialistas», eran calificados de incipientes o insuficientes para aquella tarea en los países subdesarrollados. Esto abrió el espacio a discutir cuál era el tipo de acción estatal pertinente. En algunas formulaciones este aparece como el agente que debe dar «el gran empujón» para que se desencadene un proceso de modernización y de economía nacional autopropulsada (Rosenstein-Rodan, I962). Ello equivalía a señalar que era necesario alcanzar "un esfuerzo mínimo crítico» - es decir un umbral de acción estatal que había que sobrepasar- bajo el cual el despegue hacia el desarrollo no se produciría, análogo al necesario para asegurar el vuelo de un avión.

Ello se combinó con la controversia entre una acción estatal global y comprensiva o una focal y estratégica. La primera, enunciada como del «desarrollo equilibrado", planteaba la necesidad de una intervención estatal simultánea en la demanda y la oferta de diversos sectores económicos para que se retroalimentaran y produjeran una sinergia ascendente, impidiendo, además que algún sector económico se transformara en cuello de botella del sistema (Rosentein-Rodan, I962). La segunda, partiendo que los recursos estatales eran limitados para intervenir tan masivamente, planteaba la necesidad de una intervención estatal seleccionada que produjese el máximo de impactos creadores de tejido económico (enlaces) y de economías externas que generaban múltiples rentabilidades públicas y privadas ausentes, antes de cada intervención (Hirschman, I96I).

En cierta medida, los análisis generados, más tarde, desde la noción de polo de crecimiento de F. Perroux, pueden también ubicarse en la última perspectiva señalada. Este enfoque planteaba que el desarrollo no era nunca equilibrado sino que se generaba en algunos sectores productivos y en algunos puntos en el espacio para desde allí difundirse. Lo clave era la existencia de una «industria matriz» que cumplía el rol de arrastrar a través de eslabonamientos, a una parte significativa de la economía (Kuklinski, I985). Esto llevará en los años sesenta a propuestas de creación de polos de desarrollo - transformado en un enfoque paradigmático de desarrollo regional- en zonas subnacionales consi- 
deradas atrasadas y con potencialidad de consolidar ciudades intermedias (De Mattos, 1984).

También el diagnóstico de que en los países pobres existía una gran cantidad de pequeñas empresas levantó en algunos economistas, como G. Myrdal respecto de la estrategia de desarrollo de la India, la idea que la estrategia de desarrollo debía no destruir sino tomar como base ese patrimonio (Myrdal, I957). Esto, porque una modernización económica basada en la sola gran empresa, como referencia dominante, amenazaría con generar islotes de modernidad y una sociedad fragmentada. Ello se inscribía además en la problemática de lograr armonizar crecimiento económico con creación de empleo. En elaboraciones posteriores ello será conectado con ideas de una tecnología apropiada o intermedia que pudiera conciliar crecimiento con empleo. Esto se enfrentó a un cierto predominio de la idea que siempre era mejor la máxima expansión, con la tecnología más de punta y el máximo de economías de escala en la producción (Dickson, I980).

\section{Socialismo y planificación: variante radical del desarrollismo}

El socialismo, luego de la Segunda Gran Guerra, aparece como una propuesta que se expande como alternativa al desarrollo económico capitalista para los países subdesarrollados. Esto en el contexto geopolítico de la Guerra Fría donde se inscribía la disputa por la superioridad de un sistema socioeconómico sobre otro. La vía socialista se ofreció como «atajo histórico» para producir un desarrollo de las fuerzas productivas allí en las vastas zonas del planeta donde el capitalismo, dada su fase más concentrada e imperialista, no era capaz o, en el mejor de los casos, lo haría mucho más lentamente. En ese sentido, el socialismo, en su lectura marxista, encarnado prácticamente en la URSS, y ahora en el Este europeo, estaba llamado a cumplir lo que en una visión clásica debía haber sido tarea del capitalismo. Ello sin embargo presenta cierta ambigüedad, pues los partidos comunistas de América Latina, portadores de la matriz marxista, sostuvieron por varios decenios la idea de un rol histórico a ser jugado por un capitalismo nacional ( «antiimperialista», «antioligárquico»y "antimonopólico»). En este caso, la crítica a la posibilidad de modernización por vía capitalista es puesta en el centro por la Escuela de la Dependencia, entendida por ello como una aproximación neomarxista, al cuestionar el rol históricamente progresista del capitalismo para los países dependientes. 
El objetivo central para ese propósito desarrollista era también la industrialización acelerada, impulsando las bases energéticas, la explotación de los recursos naturales de base, así como las infraestructuras en vialidad y transporte. Acento característico de la propuesta socialista fue la primacía de la industria de medios de producción, en particular aquellos referidos a los considerados sectores industriales de punta (Rutkowski, I965). La orientación industrialista planteó, a su vez, la cuestión de la extracción de capital (excedente) desde la agricultura hacia la industria y el aumento de la productividad agrícola para sostenerla, lo que, en el fondo, era una decisión sobre las condiciones de vida en el sector rural para sostener el desarrollo industrial.

Para el ejercicio de su estrategia y como principio característico, el enfoque socialista definió la necesidad de construir un «área social, estatal o nacional», la que establecía relaciones de supremacía respecto de otras formas minoritarias de propiedad y gestión: la capitalista y la pequeña producción mercantil (pequeña producción sin asalariados con destino a la venta: unidades campesinas o urbanas, como producción de cereales o servicios residenciales). La colectivización de la gran propiedad privada existente —industrial, financiera, comercial y agraria- y luego su constante ampliación se entendía como la condición básica para una modernización económica acelerada. Ella era concebida, además, como la base material para el despliegue del otro componente central del enfoque, cual era la existencia de una planificación integral de la economía, entendida, en su sentido más profundo, como expresión de que la razón humana podía construir un sistema socioeconómico apropiado a sus fines, aunque sujeta al respeto de lo que los planificadores socialistas llamaban las «leyes económicas» (Lange, 1965b). A través de esa modalidad, los teóricos y planificadores de las experiencias socialistas planteaban que se aseguraría el total uso productivo del excedente económico, impedido en el capitalismo. Ello pues el mercado dilapida producción al producir ajustes de oferta y demanda de manera ex post (sistema anárquico), a veces a través de fuertes crisis de sobreproducción y porque parte de dicho excedente es consumido suntuariamente o dilapidado por las clases propietarias y no usado para ampliar la base productiva de la economía.

En un plano concreto, la gestión planificada de la economía suponía definir y armonizar ciertos agregados, como el crecimiento armónico de las distintas ramas de la producción para que no hubiese cuellos de botella; las exportaciones con las importaciones; la expansión de los medios de pago (dinero) con la parte del producto que se distribuía bajo la forma de mercancías; y, sobre 
todo, establecer cuántos medios productivos se consagraban a producir bienes de consumo y cuántos para ampliar los propios medios de producción, determinando la tasa de crecimiento de la economía. Ello atravesado, además, por el debate acerca de la efectiva apropiación social de esos medios o de la tecnoburocratización del poder. ${ }^{5}$ Este tipo de definiciones se fueron dando en medio de permanentes tensiones que expresaban el hecho que los contenidos precisos del enfoque socialista no estaban definidos previamente a su puesta en marcha (Lange, I965a).

Así surgieron polémicas sobre los grados de centralización y descentralización de la planificación; sobre el uso de los medios administrativos o de mercado para orientar la producción; sobre el uso de los estímulos materiales o morales para reconocer los esfuerzos; sobre los grados de colectivización agrícola y las relaciones entre agricultura e industria necesarias para el desarrollo de esta última; sobre la composición entre crecimiento de bienes de producción y de consumo (Lange, I965b). Éstas no fueran discusiones sólo técnicas, sino con componentes ideológicos y grupos de interés internos, particularmente dentro de los partidos comunistas gobernantes, y que marcaron supremacías relativas o más duraderas de unas corrientes sobre otras. Estas tensiones hicieron parte del debate y marcaron diferencias de proyectos socialistas en la URSS, Europa del Este, Asia, África, el Mundo Árabe y América Latina.

La caracterización presente del socialismo es compleja. La crisis política terminal del socialismo soviético y del Este europeo disminuyó las experiencias socialistas actualmente existentes y el propio carácter socialista de éstas resulta discutible dadas la importancia mucho mayor de la propiedad privada, del capital extranjero, de los mecanismos de mercado, en China, Vietnam y Cuba, lo que ha tendido a aumentar las diferenciaciones socioeconómicas que se producen en su interior (Centre Tricontinental, 200I). Esas orientaciones pueden tener explicaciones al interior de esos países que intentan justificarlas en términos del marco teórico-conceptual «marxista». Por ejemplo, en China señalándose que aún el capitalismo y la propiedad privada pueden jugar roles progresistas o, en Cuba, que un error posible puede haber sido un intento de desarrollo socialista ( «condiciones subjetivas») cuando las «condiciones objetivas» estaban demasiado inmaduras.

5. Esto se refiere al ideario socialista de una efectiva apropiación de los medios de producción por los trabajadores y las tensiones con el peso decisivo que fue tomando la tecno-burocracia desde el aparato estatal (Kardelj, I976). 


\section{El estructuralismo latinoamericano: capitalismo periférico, dependencia y revolución}

Desde fines de los años cuarenta la preocupación por el desarrollo vio surgir una corriente estructuralista latinoamericana nucleada en torno a la Comisión Económica para América Latina (Cepal) que teórica y programáticamente acompañó los procesos de industrialización que habían comenzado en varios países del continente, desde fines del siglo XIX, y con la primera guerra y de la depresión de los años treinta. Una originalidad de dicha institución fue introducir la noción de sistema económico mundial y de división internacional del trabajo como base de la conformación de un capitalismo periférico y de un capitalismo central. El primero caracterizado por países limitados a ser productores y exportadores de productos primarios y compradores de manufacturas desde los países centrales.

Para la Cepal esto impedía proyectar una modernización de largo alcance dada la realidad de baja elasticidad de la demanda de productos primarios lo que, a su vez, comparada con la alta elasticidad de la demanda de los productos industriales, conducía al deterioro de los términos de intercambio para los países periféricos. Esto último también influido por el peso que en el mercado mundial tenían las empresas de los países centrales, dado el mayor poder de los capitalistas y asalariados en estos países, lo que hacía que el aumento de su productividad se tradujese en mayores ganancias y salarios en el Centro y no en precios más bajos para la periferia (Rodríguez, I980). Esto constituyó una fuerte crítica a la afirmación liberal clásica (A. Smith y D. Ricardo) sobre las ventajas que siempre aportaría la especialización productiva entre países, de acuerdo a las «ventajas comparativas». Constituía, además, sacar el problema de la explicación del subdesarrollo de los solos términos de una sociedad tradicional aún insuficientemente modernizada y llamar la atención sobre una estructura económica mundial como factor central de bloqueo.

Ello condujo a la propuesta de pasar a una industrialización programada con protagonismo del Estado y de un empresariado nacional que debía consolidarse en el propio proceso. Aquella «industria naciente», ${ }^{6}$ como condición

6. Noción que había sido usada un siglo antes por la «escuela histórica alemana» para justificar un proteccionismo alemán y oponiéndose a concederle a la economía liberal inglesa el valor de una verdad universal en sus doctrinas del libre comercio (Blaug, 200I). 
de emergencia y sustentación debía, al menos durante una primera etapa, ser protegida, principalmente a través de aranceles, de las importaciones de países industriales. Se la entendía comenzando por manufacturas simples de consumo final, sustitutivas de importaciones, y desde allí avanzando hacia etapas más complejas en la medida que la propia expansión iba haciendo rentables la producción interna de bienes intermedios o de capital. El centro de gravedad en cuanto a demanda era el mercado interno de los países y de allí la calificación de «desarrollo hacia dentro». Se planteaba que, estratégicamente, el proceso de industrialización debía financiarse con ahorro nacional, pero en una primera etapa por el bajo ahorro propio de los países pobres, obligaba a acudir a capital externo que la Cepal vio especialmente relacionado con fondos de cooperación internacional, aunque también comprendiera capitales privados de naturaleza productiva (inversión directa) o financiera (préstamos comerciales) (Prebisch, I95I). De manera optimista el proceso se imaginaba con círculos virtuosos entre crecimiento industrial, mayores ingresos, mayor ahorro interno y mayor capacidad interna de financiamiento de la inversión, y entre crecimiento industrial, mayor empleo, mayores ingresos, mayor demanda e incentivo a mayor expansión industrial.

Sin embargo, la dinámica de la industrialización latinoamericana fue planteando problemas y nuevas propuestas que se hicieron parte del ideario cepaliano. El proceso reclamaba importaciones de tecnología, insumos y materias primas que no eran posible financiar con estructuras monoexportadoras, en algunos casos de propiedad extranjera; la ampliación de los mercados internos fue limitada por razones demográficas y por la mala distribución del ingreso; la agricultura por un lado expulsaba y por otro mostraba incapacidad para abastecer a una población crecientemente urbana; el ahorro interno era bajo y aparecía limitado, al menos en parte, por las pautas de consumo de las clases ricas bajo el «efecto demostración» de los países avanzados; ${ }^{7}$ la creación de empleo moderno industrial y urbano no era suficiente y muchos migrantes rurales se transformaban en desempleados o subempleados urbanos. En ese contexto problemático varias políticas fueron agregándose o cobrando mayor fuerza dentro del ideario industrialista cepaliano: la reforma agraria, la integración económica y la formación de un mercado latinoamericano, las políti-

7. De acuerdo a Celso Furtado, en América latina, particularmente por la conducta de sus clases ricas, se produjo antes una modernización en el consumo que en las estructuras productivas (Furtado, I970). 
cas de redistribución del ingreso, las capacidades programadoras del Estado y las políticas de desarrollo regional (Prebisch, 1963).

Pero algunos análisis estructuralistas latinoamericanos se fueron radicalizando más en su crítica al capitalismo y dirigieron su atención hacia las estructuras de poder externas e internas que mantenían las situaciones que bloqueaban la industrialización. Surgió el diagnóstico de un cierto agotamiento de la etapa de sustitución fácil y dificultad de pasaje a una etapa más compleja. Nutriéndose de una vertiente «neomarxista» el enfoque de la dependencia planteó las dificultades o la imposibilidad del desarrollo bajo situaciones de capitalismo dependiente. Un antecedente analítico inaugurador fue el de P. Baran que señaló que el excedente económico potencial de los países capitalistas pobres - es decir la parte del ingreso posible de ser usado para expandir las fuerzas productivas sin amenazar el consumo necesario para la reproducción de la sociedad - no se usaba para esa expansión por varias razones: las clases agrarias lo usaban en consumo suntuario, otra parte se escapaba directamente a los países centrales como utilidades de compañías extranjeras, otra lo consumía una burocracia estatal y también había corrupción (Baran, I969).

Los análisis dependentistas posteriores plantearán que en la base de todo lo anterior estaba el hecho que las estructuras y agentes económicos internos de los países dependientes son fuertemente moldeados por los intereses y las orientaciones de los países del capitalismo central. En definitiva, América Latina, como otras regiones dependientes, habían sido insertadas «desde fuera» en una economía mundial, para servir a los procesos capitalistas de acumulación de los países centrales, variables según cada momento del proceso de acumulación mundializado: provisión de metales preciosos, de alimentos, de materias primas, mercado para manufacturas y para bienes de capital. Ello no constituía falta de modernización sino una de tipo dependiente, ligada al proceso de expansión capitalista mundial, en que la dinámica interna no obedecía a impulsos endógenos. El análisis del subdesarrollo llevaba entonces a comprender y «denunciar» el sistema capitalista mundial y su imperialismo, visto desde el punto de vista de su significado para los países dependientes (Dos Santos, I972).

En cuanto a ese significado, el enfoque dependentista recogerá parte del análisis estructuralista cepaliano en curso acerca de los problemas de la industrialización, pero enfatizará la crítica al grado de dependencia y desnacionalización que empezó a tener aquélla. En ese marco interpretativo los empresarios nacionales no existieron como tales, sino como eslabón y sometidos de 
los agentes internacionales -en lo financiero, en lo tecnológico, en lo comercial- lo que los inhabilitaba para encabezar un proceso nacional de desarrollo, configurando una «lumpen burguesía» como los denominó A. G. Frank. Esa falta de autonomía se expresaba en un déficit esencial que presentaba la industrialización latinoamericana que era la no existencia de un sector nacional de medios de producción. Todo esto llevaba a la necesidad de un proyecto de desarrollo socialista con un rol central del Estado, la planificación y centrado sobre otras fuerzas sociales, lo que suponía un proceso de cambio radical y en que quedaban conectada ruptura del subdesarrollo con revolución (Marini, I974). Ello ocurría, además, en un contexto de fuerte movilización social y política continental y de un aumento del peso de los países no alineados en el concierto internacional. Este enfoque dependentista, si bien se ve abruptamente abortado por las nuevas circunstancias políticas de América Latina que vio surgir los regímenes de seguridad nacional, ha sido recogido parcialmente en las más actuales perspectivas del sistema y la economía mundo a través de las nociones de países centrales, periféricos, semiperiféricos y arenas exteriores (Wallerstein, I984).

\section{Debates normativos sobre desarrollo: pobreza, equidad, naturaleza y cultura}

En los años setenta surgen también cuestionamientos sobre la definición de desarrollo económico, abriéndose un campo más visible de tipo normativo, en que lo común, dentro de una diversidad de aspectos, es poner en cuestión su reducción al crecimiento o desarrollo de las fuerzas productivas y al PIB como indicador central (Bustelo, I998). Una primera vertiente son las consideraciones ecológicas. El llamado «Informe de Roma» establece un hito al mostrar que el crecimiento económico y demográfico ejercía efectos destructivos de escala global sobre el medio natural y que debían, por lo tanto, ser controlados (Meadows y otros, I972). Una serie de problemas que van a entenderse como de escala planetaria adquieren relevancia: aumento de la desertificación, deterioro de la capa de ozono, contaminación del aire, agotamiento de recursos naturales, pérdida de diversidad animal y vegetal. Las ideas de finitud o límites de los recursos y la atención a la reproducción del mundo físico hacen entrada en el análisis económico. La clásica referencia sobre la subutilización de recursos en los países pobres da paso a la visión de sobreexplotación mundial de ellos. En su expresión más crítica se da lugar a un cuestionamiento de la modernidad 
caracterizada como antropocéntrica, que no asume lo humano como parte de un cosmos envolvente dentro del cual existe, se reproduce y debe establecer relaciones de armonía.

Frente a esto, algunas vertientes plantearon la necesidad del «crecimiento cero» que comprendía a la producción, especialmente en el norte, y a la demografía, especialmente en el sur. Esto enfrentó dificultades de aceptación tanto de cara a la modernidad todavía incumplida de los países más pobres y en cuanto ponía en cuestión la lógica del sistema capitalista basado en la permanente acumulación de capitales y de aumento del consumo, en los países industrializados. Las economías socialistas, preocupadas también del «desarrollo de las fuerzas productivas» no tuvieron cercanía con esas propuestas. Así, las nuevas consideraciones ecológicas fueron aplacadas y terminaron entendiéndose, en los planteamientos más oficiales, armonizables con las estrategias de crecimiento, dando nacimiento a las nociones de desarrollo sustentable, sostenible o durable.

Esto condujo a su vez a un debate sobre el rol del Estado y a los acuerdos internacionales para asegurar dicha armonización. Pero también, con el tiempo, dieron origen a aproximaciones liberales que van a enfatizar el rol del mercado a través de incorporar en los precios ciertos costos ambientales, creando incluso mercados de derechos (bonos) de contaminación, junto a una afirmación optimista de que aquel generará un amplio campo de incentivos y oportunidades de inversión para «bienes y servicios ecológicos o verdes». Ello establece una importante fosa de separación con planteamientos ecológicos sobre la necesidad de cambios profundos en las pautas de consumo, tecnologías productivas y en los estilos de vida, y un rol activo de los sistemas políticos y el control social sobre la economía (Verhaegen, I998).

Una segunda corriente normativa dio origen a un «enfoque social» sosteniendo que sólo puede hablarse de desarrollo si junto al aumento del producto hay mejoras en el empleo, en la distribución del ingreso y en la satisfacción de las necesidades básicas. La ocupación por el empleo recogió la influencia de la Organización Internacional del Trabajo (OIT) motivada, a su vez, por estudios de principios de la década de los setenta, en África, que demostraban que en las ciudades de los países pobres, en medio de un intenso proceso de migración campo-ciudad ocurrido, el fenómeno más característico era no tanto el desempleo abierto sino la existencia de las actividades económicas «informales» (Portes y Haller, 2004). Éstas constituían un trabajo precario e ingresos bajos, aunque eran demostrativas del dinamismo de los pobres urbanos para generar iniciativas de sobrevivencia y no se les podía entender como sujetos anómicos 
o desintegrados como en las anteriores teorías de la marginalidad. Asegurar la creación de más y mejor empleo («formal») fue visto como la tarea central del desarrollo, abriéndose hacia la necesidad de influir en las trayectorias sectoriales y tecnológicas del aparato productivo.

La dimensión de la distribución del ingreso es expresada a raíz de la evidencia de la gran desigualdad existente, la que aparece aun mayor en los países más pobres, en los que las tendencias del estilo de crecimiento son hacia su reproducción. Dicho objetivo redistributivo aparecía en sinergia con la creación de más empleo en tanto se consideraba que una mejor distribución aumentaría la demanda agregada de bienes más intensivos en trabajo. La manera en que este enfoque plantea el mejoramiento distributivo es a través de lograr que cada punto adicional de crecimiento sea mejor distribuido que el producto anterior y fue popularizado a través de la idea de crecimiento con redistribución (Chenery y otros, 1974). Ello eludía lo conflictual de distribuir la riqueza antes concentrada, como la propiedad de la tierra u otros activos. Sin embargo, esta estrategia presentaba serias limitaciones para producir cambios más o menos perceptibles en plazos razonables y, a la vez, medidas concebidas menos conflictivas, como cambios en los niveles y estructuras de impuesto, se mostraron igualmente difíciles, dadas las relaciones de poder y la resistencia de las clases pudientes. En ese marco, una línea crítica planteará la imposibilidad de mejoramiento en la distribución de ingreso sin redistribución de activos económicos.

Finalmente, estas consideraciones sociales terminaron concentrándose en la dimensión de las necesidades básicas: el desarrollo debía significar la disminución de personas que estaba bajo la línea de su satisfacción. Ello significaba un acuerdo sobre qué constituye lo básico y sobre los umbrales críticos en que un componente — como la salud, la vivienda o la alimentación— puede ser considerado que está siendo satisfecho, lo que determina un campo discutible que no es estrictamente técnico ni puramente biológico. Así, por ejemplo, la recreación o de la participación como necesidades básicas pueden ser o no consideradas o serlo con distinta jerarquía; asimismo, como en el caso de la educación, es necesario precisar cuál es un mínimo aceptable. Este enfoque se asentaba sobre el trasfondo histórico del avance y consolidación de la idea de Estado de Bienestar, considerado como una contraparte institucional de la consagración de derechos económicos y sociales.

Desde un punto de vista crítico, esta focalización en las necesidades básicas puede verse como una minimización de lo social al expresarse en la fijación de objetivos muy básicos que permiten avances estadísticos pero que tienen 
significados limitados. Asimismo, porque el logro de lo básico queda separado de la distribución de los ingresos y de la riqueza y puede coexistir con un aumento de la desigualdad (Bustelo, I998). Sin embargo, esta aproximación tuvo la importancia de aportar a una discusión sobre el tema de las necesidades básicas que, también permitió expresiones más amplias e integrales como las de M. Max Neef (I985) y que también se ha prolongado y renovado en la noción de desarrollo humano de los años noventa. Asimismo, combinada con consideraciones ecológicas y psicosociales contribuyó a la emergencia de la noción de calidad de vida.

Por último, es interesante considerar dentro de estos debates normativos de los años setenta una vertiente menos influyente que las dos anteriores, de origen nórdico, que busca articular de nueva forma el desarrollo con la participación y la cultura (Dag Hammarskjöld, I975). Esto se realiza a partir de la valorización de las «comunidades locales» como sujetos de su desarrollo - y no objetos- acercándose a una perspectiva de «desarrollo de base». Aquéllas son comprendidas como poseedoras de una cultura, capacidades y recursos, propios. De la identidad cultural se infiere que deben ser esas poblaciones locales las que determinen sus metas de desarrollo y de la posesión de capacidades y recursos se deriva la necesidad de estrategias bajo una modalidad endógena, colectiva y participativa.

Dentro del panorama largo del debate sobre desarrollo, algo significativo de esta corriente es que, por un lado, cuestiona que aquel sea entendido con un contenido único y universal, sino que debe ser correspondiente con la cultura de cada comunidad territorial, aproximación que será profundizada por corrientes posteriores como las del etnodesarrollo. Por otro, establece una ruptura con la idea que el desarrollo puede ser aportado por capas técnicas modernas hacia poblaciones entendidas como objetos y beneficiarias de las políticas de desarrollo -disociando sujeto y objeto del desarrollo. Esta perspectiva que valorizó las escalas locales de desarrollo estableció posteriormente sinergias con ideas paradigmáticas como las de tecnologías apropiadas o intermedias (Dickson, I980) y de «lo pequeño es hermoso» (Schumacher, I987).

\section{Enfoques globalizadores: exportaciones, neoliberalismo, neoestructuralismo y capital humano}

Al calor de la globalización, asumiéndola como proceso irreversible y positivo, se generan en los años ochenta y noventa enfoques que hacen de la en- 
trada exitosa en aquélla en el eje del desarrollo, el que, a su vez, vuelve a ser fundamentalmente recentrado en el crecimiento. Un grupo de países asiáticos — particularmente Corea y Taiwán — sirven de antecedente paradigmático para fundamentar los buenos resultados a los que conducirían estrategias abiertas a los mercados externos bajo una estrategia de crecimiento y cualificación de las exportaciones (estrategia de «sustitución de exportaciones»). Se les contrapondrá a lo que habrían sido las estrategias fracasadas de América Latina, India y algunos países africanos utilizando modelos proteccionistas y de industrialización hacia el mercado interno (Lanzaroti, I990).

En realidad lo anterior constituyó un eje del enfoque neoliberal emergente que repuso en grados radicalizados la idea que la clave para el desarrollo era dejar que la economía fuese regulada por el mercado y desde procesos de acumulación de los agentes privados en escenarios competitivos (L'Heriteau, I986). ${ }^{8}$ El primero aseguraba una asignación óptima de los recursos productivos en función de las demandas de los consumidores y era presentado con una superioridad «ética» sobre la acción reguladora desde la política en tanto espacio de relaciones voluntarias, no coactivas, entre los individuos. Para que ello ocurriese era necesario que los precios de los bienes y servicios fuesen dejados «libres» expresando las escaseces y valoraciones sociales reales y permitiendo guiar correctamente las decisiones de cada agente. Ello permitiría, en el marco de una economía globalizada, sin fronteras «artificiales», que cada país y territorio se especializara en aquellos productos en los que ofreciera ventajas comparativas y adquiriera los otros a través de importaciones (incluyendo al capital y al trabajo). El espacio económico nacional fortalecido, propio de los proyectos de modernización nacional de los decenios anteriores, deja de ser la referencia central y el mercado interno cede la jerarquía a la inserción exitosa en el mercado mundial (Amin, I993).

Ese proceso es concebido como liderado por empresariados internacionalizados releídos como agentes casi únicos de la acumulación y en que los países deberán crear las condiciones para atraer el máximo de capital y de capitalistas hacia sí. Dejan de tener una importancia específica la formación de un empresariado nacional y la propiedad nacional de los recursos, evaluando la llegada

8. Esas visiones venían ya de los años cincuenta y combatieron de entrada los proyectos nacionales de industrialización nacional por intentar romper la natural división internacional del trabajo proveniente de la realidad de las ventajas comparativas dictadas por el mercado y asignarle un rol motor al Estado. 
de capital extranjero y la transnacionalización de la economía como signo de éxito del proceso de desarrollo, de la confianza en él y de una vía de mayor inserción en la economía global.

Bajo esas premisas, el «programa de acción» del enfoque neoliberal apuntó al «desmontaje del Estado» en sus dimensiones desarrollistas, bienestar y keynesiana que habían acompañado el siglo XX — constituyendo de acuerdo a V. Hayek el «camino a la servidumbre»- y que fueron sindicados como la base de los problemas de las economías del Sur, del Norte y del Este: la inflación, el ahogo de la iniciativa privada, la mala asignación de recursos, el estancamiento, la ineficiencia. Para dicho enfoque, esto expresaba el peso de ciertos grupos - particularmente atacados serán los sindicatos aunque también algunos sectores empresariales- que a través de ello obtenían beneficios («rentas distributivas») y el de una burocracia estatal que se reproducía en su interior. El Estado debía limitarse a asegurar condiciones de estabilidad política (orden interno); estabilidad macroeconómica a través de una política monetaria y fiscal que impida fenómenos inflacionarios; disminuir la extracción de excedentes desde la economía (impuestos), considerados como desincentivos para los inversores privados; flexibilizar los mercados del trabajo disminuyendo los costos de contratación y despido; crear condiciones institucionales para incentivar la inversión privada en áreas de interés público y con fines sociales, privatizando y mercantilizando áreas enjuiciadas como perjudicialmente monopolizadas por el Estado (salud, educación, transporte, seguridad social) (Emmerij, I998).

Algunos fenómenos empíricos y de orden teórico van a generar un liberalismo algo más moderado: la precarización económica y social en lugares en que se aplicaron políticas de esa naturaleza ( «los ajustes estructurales»); el surgimiento de una literatura sobre las «fallas de mercado» que mostraba sus imperfecciones para asignar los recursos, incluyendo las externalidades negativas y positivas que no procesaba; o las relecturas mucho más objetivas del «éxito asiático» que terminaron por mostrar el rol clave que había jugado el Estado en el impulso de ciertos sectores productivos, en la imbricación compleja entre apertura y proteccionismo, en su influencia en las altas tasas de ahorro y las pautas moderadas de consumo, y en la realización de reformas agrarias radicales. Esto hace que la discusión respecto del importante rol del Estado en los países asiáticos abandonara la lectura liberal y se centrara en si el Estado había sido un complemento clave del mercado o había sido un «distorsionador del mercado» (Wade, I999). Es por ello que, paradojalmente, tendió a sustentar 
posiciones neoestructuralistas. Es importante destacar, además, que el «éxito asiático» se había desarrollado dentro de condiciones políticas fuertemente autoritarias. Esto llevara a una inflexión en que el Estado hasta ahí entendido básicamente como un problema empieza a ser considerado como parte de la solución a ciertos desequilibrios y el discurso bruto deja un lugar central al de su modernización (Rodrik, I999).

Un agregado importante que ha tenido el enfoque liberal es la noción de desarrollo endógeno que destaca, a partir de estudios de Solow en la economía norteamericana, la centralidad del progreso técnico y capital humano, en el crecimiento (Jones, I998). Un grupo de autores, a diferencia del planteamiento original, sostiene que aquéllos son endógenos al proceso económico mismo, dado que las decisiones de los individuos y empresas por hacer aumentar aquellos factores - tomado como inversiones en capital humano o innovaciones - radican en las condiciones institucionales que permitan compensar adecuadamente esas conductas. Ello le concede un lugar central a la defensa de la propiedad privada intelectual y a los beneficios a obtener de ella. A la vez, dado que en las decisiones individuales no es posible incorporar todo el beneficio que tiene para cada uno que otro también aumente su capital de conocimientos, la inversión dejada al puro mercado es subóptima y abre la necesidad de una acción del Estado, dada la existencia de externalidades positivas (Jones, I988).

Asumiendo la perspectiva liberal de la centralidad de insertarse de manera exitosa en la globalización como el centro de una estrategia de modernización, surge en América Latina el neoestructuralismo, el que adquiere visibilidad en los años noventa. Ubicado dentro de la tradición estructuralista latinoamericana afirmará, sin embargo, que dicha corriente en el pasado, en sus expresiones cepalianas y dependentistas, habría exagerado su confianza en el Estado y su desconfianza en el mercado; no habría dado toda la importancia necesaria a los equilibrios económicos de corto plazo (nivel de precios, balanza de pagos), privilegiando sólo las estrategias de largo plazo; y no le habría dado la importancia debida al desarrollo exportador como eje del crecimiento.

La diferencia con el neoliberalismo quedaba establecida en que para el neoestructuralismo la inserción internacional de las economías como condición del desarrollo no podía ser sólo orientada por el mercado. De ser así, ello limitaría a los países latinoamericanos a retornar estructuras productivas especializadas en ventajas de productos primarios (recursos naturales), retomando un clásico postulado crítico del estructuralismo latinoamericano. Una situa- 
ción tal fue denominada una "competitividad espúmea» y de tipo rentista, pues dependía más de los recursos naturales que se poseían que del progreso técnico nacional. Para los neoestructuralistas ello conducía a un modelo económico sobreexplotador de recursos naturales, con baja generación nacional de ciencia y tecnología, limitado número de trabajos calificados y bien remunerados y, a raíz de ello, una mala distribución del ingreso (Fanjzilber, I990).

La forma de evitar esa situación suponía una política activa del Estado con tareas en la infraestructura, en el apoyo a las empresas más pequeñas, en castigar la sobreexplotación y exportación de recursos naturales en bruto, en el fomento de la educación, ciencia y tecnología, tomando, justamente, a los países asiáticos como ejemplo de Estado activo. Solo así se podría generar una inserción internacional basada en el progreso técnico, con alto valor agregado interno, menor cantidad de recurso natural por unidad de valor exportado, mayor cantidad de puestos de trabajo calificados y, finalmente, una mejor distribución de ingreso. Una particular importancia se le concederá al rol estatal en educación, ciencia y tecnología y formación de capital humano —en parte también inspirado en algunos países asiáticos- estableciendo un punto de encuentro aunque con diferencias, con las antes señalada aproximación neoliberal (Sunkel, I99I).

Todo ello fue simbolizado con la noción de «desarrollo desde dentro» y de «competitividad sistémica», la que depende no de empresas aisladas sino de la calidad institucional de los sistemas nacionales. Esto incluía los grados de integración social de un país, definido por una cierta equidad en la distribución de los beneficios del crecimiento, lo que, por tanto, era considerado positivo para una mayor competitividad internacional. En este sentido, para los neoestructuralistas los «equilibrios macrosociales» se agregan a la necesidad de los «equilibrios económicos» como condición de una inserción exitosa en la economía mundial.

\section{Otras perspectivas y contestaciones recientes}

En paralelo, o en cuestionamiento al predominio del enfoque liberal de los últimos decenios, surgen otros que ejemplifican bien las diferencias y antagonismos que constituyen al campo del desarrollo económico y que prolongan aproximaciones ya emergidas en decenios anteriores. El de mayor reconocimiento ha sido el enfoque de «desarrollo humano», posible de situar en la corriente más larga del «enfoque social», que se separa de hacer del crecimiento 
del producto un fin en sí mismo. A. Sen, el principal teórico de este enfoque, entenderá al desarrollo como un proceso en que se expanden las capacidades de las personas con los consecuentes aumentos del arco de opciones a su disposición; en definitiva, de su libertad (Sen, 2004). Para ello es necesario que la sociedad asegure una serie de condiciones básicas, sino las personas verían seriamente restringidas su arco de libertad. En su plano operacional ello ha llevado a establecer condiciones en el terreno de la educación, de la salud y de los ingresos que debiesen ser aseguradas para expandir las capacidades propias. La medición de estos factores conduce a la construcción de un índice de desarrollo humano que permite observar la situación de un país o territorio y que es considerado complementario o alternativo del PIB. Esto permite observar que países que figuran sobre otros de acuerdo al indicador del PIB per cápita caen por debajo cuando se consideran el conjunto de los aspectos señalados. Debe sí hacerse notar que, operacionalmente, el indicador resulta bastante precario o restringido respecto de la riqueza normativa de la noción que le da origen.

Fortaleciendo miradas desde la cultura, también ha madurado el enfoque del etnodesarrollo que plantea que es la referencia a la cultura de cada pueblo lo que debe hacer de referencia central para pensar su desarrollo, en específico desde la perspectiva del rescate de los pueblos originarios y sus luchas por el reconocimiento. Desde esa afirmación, el proceso de globalización es visto como amenazante en cuanto fundado en una idea única del desarrollo y homogeneizador de las culturas diversas. Ello lleva a simpatías por estrategias que combinan la resistencia con el despliegue de capacidades e identidades propias y el uso de instrumentos del progreso científico para enfrentar las necesidades de una comunidad local (Bonfil y otros, I982).

Esto suele establecer conexiones con otra corriente, promotora de una idea de desarrollo que privilegia a los actores locales como protagonistas y al mesonivel como escala de acción, en que se busca articular desarrollo con participación y democracia. El desarrollo local, en esta perspectiva, es visto como alternativa frente a proyectos centralistas y verticales de desarrollo y crítico a la globalización caracterizada como un proceso que «funcionaliza» y jerarquiza a los territorios según las necesidades de la acumulación económica y la competencia global. Frente a ello dicho enfoque valoriza los territorios como espacios concretos de vida de las personas, con su historia y cultura (González, I995). En algunas de sus variantes ello va fuertemente ligado al rescate de iniciativas económicas locales existentes y que suelen comprenderse como una 
economía popular territorializada aunque conectada en redes más amplias. Para algunos autores, en esas prácticas se expresa una racionalidad solidaria que constituye la base de otra economía o de una economía plural (Laville y García, 2009). Sin embargo, debe mencionarse que también hay una valorización económica de los territorios locales desde la perspectiva de estrategias de competitividad, en la lógica de territorios ganadores y perdedores, y en que se van a destacar sobre todo las economías internas al territorio y sus instituciones y su identidad como «capital competitivo» en la globalización.

También el panorama crítico muestra evoluciones de críticas más antiguas en los terrenos del daño y la destrucción del mundo vegetal y animal y del desequilibrio en los sistemas naturales. Desde aquí se plantea la necesidad de una transformación radical que permita revertir el proceso de destrucción planetaria. Se denuncia a la idea del desarrollo sustentable como una orientación que permite mantener la ideología de un crecimiento permanente (Apostel, 200I). Ello en tanto no altere con profundidad las pautas de consumo y producción vigentes.

Pero también en un ala más radical han surgido críticas al objetivo mismo del desarrollo entendido como una noción surgida en Occidente y que se ha buscado imponer sobre el resto. Ésta constituye una radicalización de las corrientes del «otro desarrollo» o «desarrollo alternativo» nacidas en los años setenta y se postula como un rechazo de raíz al desarrollo en cualquiera de sus versiones o posiciones. Esto porque es aquél la fuente del problema y no su naturaleza particular expresada en tal o cual corriente u orientación en tanto en todas ellas sigue presente la racionalidad del crecimiento, aun cuando sea con adjetivos (Latouche, I988). En términos generales ello da origen a una propuesta de "posdesarrollo» a favor del decrecimiento y de una simplicidad voluntaria del consumo (Latouche, 200I).

Esta descripción rápida de enfoques críticos en evolución permite constatar que la discusión del desarrollo es una discusión viva o latente que está lejos de fundamentar la idea de un «fin de la historia». También tiene la importancia de mostrar una brecha entre un conjunto amplio de ángulos críticos al estado de cosas en curso y la fuerza material del proceso fáctico de globalización liberal de los últimos decenios. Esa brecha genera un panorama incierto y sólo aparentemente consolidado y me parece que será el sustrato de crecientes debates en el futuro inmediato, aunque no sean claros los cambios a ocurrir. La manera de enfrentar eso es también fuente de debates. Si tomamos la corriente "alter mundialista» como referencia podemos, por ejemplo, observar tendencias que 
privilegian actuar en el nivel global, otras fortalecer la acción de bloques regionales supranacionales, otras fortalecer nuevamente los Estados nacionales y, por último, tendencias partidarias de fortalecer la acción y los agentes locales (Polet, 2008).

\section{Reflexiones finales}

De lo expresado se puede concluir que el área de los enfoques y estrategias de desarrollo ha estado compuesto de variadas interpretaciones y propuestas y no puede sino comprenderse como una en permanente despliegue y disputa. Han existido referencias paradigmáticas como modernización, industrialización, dependencia, necesidades básicas sustentabilidad, capital humano, globalización y otras, que van reflejando movimientos teóricos, nuevas circunstancias históricas y relaciones de fuerza en la sociedad. Un amplio entramado de aproximaciones se extiende desde la enunciación de círculos viciosos del subdesarrollo hasta los cuestionamientos de la racionalidad del crecimiento, desde las afirmaciones de subexplotación de recursos naturales hasta las denuncias sobreexplotación, desde la idea de falta de capital hasta la supremacía de capital financiero, etcétera.

En ese camino, además, aparecen recurrentemente consideraciones, pero que pueden serlo de manera opuesta respecto de sus virtudes o vicios, como el comercio internacional, el rol del Estado, la planificación y el mercado o la consideración de las culturas locales. Ello incluye, en especial en los decenios recientes, el debate y las inflexiones respecto de la misma noción de desarrollo. En la medida que el surgimiento de éste como referencia para la política debe entenderse como «refracción» (prolongación y desviación) de la idea de progreso que acompaña a la modernidad, los propios cuestionamientos a esta última, como época de la humanidad, revierten como dudas sobre la racionalidad del desarrollo «realmente existente». En contraste con una marcha económica que, aunque con crisis, sigue produciendo acumulación, progreso técnico y consumo, se debe reconocer que la duda sobre las bondades de desarrollarse se ha instalado en la propia historia de dicha noción. La emergencia última de la idea de crisis civilizatoria y de la necesidad consecuente de "políticas civilizatorias» da cuenta de ello (Hinkelammert, 200I).

Una parte voluminosa de esta historia ha estado marcada por la idea de existencia de una cierta trayectoria más o menos universal y racional que comprendía la industrialización. Era el pasaje de una civilización agrícola y rural a 
otra industrial y urbana, más ampliamente, el pasaje de sociedad tradicional a sociedad moderna. En general, como dijimos, ello se impuso a visiones, como las del populismo ruso o Gandhi, que buscaron rescatar modos comunitarios de existencia campesina y construir una bisagra que equilibrara aquéllos con el mundo nuevo de la tecnología, la productividad, la fábrica, la proletarización, el aumento de capitales. A la vez, implicó disputas, en particular por parte del estructuralismo latinoamericano contra sostenedores ortodoxos de las ventajas comparativas que justificaban especializaciones primarias de ciertos países dentro de una división internacional del trabajo que se diagnosticaba como favorable a todos y cada uno de ellos.

En el encuadre de aquel gran objetivo industrializador, quedan aprehendidos diversos y amplios debates sobre estrategias precisas, sobre las formas de desencadenar, acelerar o culminar ese proceso y, en particular, sobre derribar los factores que la impedían o bloqueaban: los planteamientos de una industrialización que va de lo simple a lo complejo o que pone acento inicial en los bienes de producción, que utiliza la tecnología más avanzada o la que asegura el máximo de empleo, que extrae más o menos excedentes y población de la agricultura, etcétera, constituyen corazones de ese debate y constituyeron la cuestión del desarrollo económico (Baldwin, I967). En ello queda también aprehendido el debate sobre el tipo de relaciones económicas internacionales que sería beneficioso para un país y que se moverá entre la reafirmación radical de las ventajas comparativas, un proteccionismo selectivo, o la denuncia del imperialismo y su extracción de excedentes desde los países periféricos. Desde posiciones opuestas, a su vez, con el tiempo, el ecologismo, y parcialmente el neoliberalismo, levantarán fuertes impugnaciones al proyecto industrializador.

$\mathrm{El}$ anacronismo o actualidad de esas discusiones pareciera que debe ligarse a la cuestión del «nivel de vida» o «condiciones materiales de la existencia» que se consideren deseables. Al respecto, debemos tomar nota que el sustento en legitimidad de la necesidad del crecimiento económico - y con ello las preocupaciones y valoraciones sobre la productividad, el ahorro, la inversión, el progreso técnico, la ciencia aplicada y la industrialización- estuvo en que ello permitiría superar un estado de miseria material y de línea de sobrevivencia en que había existido y existía la humanidad. Aún más, permitiría arribar a una situación de abundancia que actuaría como base de un nuevo estadio de libertad y bienestar. Es lo que dibuja Rostow en su idea de sociedad moderna, pero también es la cara progresista, aunque perecedera, que Marx ve en el rol histórico del capitalismo y que abrirá camino al comunismo. Constituyó, 
asimismo, una razón central en la justificación de roles nuevos del Estado que iban más allá del keynesianismo; y está en la base de la crítica dependentista al capitalismo periférico en tanto sistema limitado o inhabilitado para cumplir aquella tarea. En definitiva, el mejoramiento de las condiciones materiales de la existencia y el dejar atrás la línea de la sobrevivencia constituyó una «ética del desarrollismo», en sus diversas variantes. Dentro de ese encuadre se hacen inteligibles múltiples enfrentamientos sobre estrategias y políticas.

Ese piso de fondo se ha visto simultáneamente fortalecido y contestado. La aproximación neoliberal y aun del actual socialismo realmente existente -China, Vietnam, especialmente - se enmarcan y argumentan sus acciones en nombre del crecimiento bajo ideas como del desarrollo de capital humano, la modernización de la gestión empresarial, determinadas políticas económicas internacionales - más abiertas o reguladas - y otras materias.

Sin embargo, por otro lado, desde la segunda mitad de los años setenta se han levantado contestaciones a ese basamento. Primero, fueron argumentos ecológicos referidos a los efectos intensamente destructivos del estilo de crecimiento sobre la naturaleza. Este punto de mira puede redefinir el juicio sobre diversos aspectos del funcionamiento de la economía como, por ejemplo, la intensa globalización que hace aumentar enormemente el comercio a distancia y con ello el uso de transporte, lo que es una causa clave de la producción mundial de contaminación. Luego se generaron visiones que pusieron en duda la relación estrecha entre crecimiento y bienestar, mostrando que esas «curvas» tendían a separarse en el tiempo y cada adición al producto aportaba menos al bienestar. Finalmente, enfoques culturalistas que cuestionaron que la necesidad de crecer fuera propia de todo pueblo. Estas perspectivas críticas, cuando se relacionan con las específicas formas en que ocurre el crecimiento, fortalecidas en los últimos decenios, conducen a la denuncia de la acumulación capitalista globalizada, comandada por grandes empresas trasnacionales.

Frente a este punto de fondo no puede eludirse la discusión normativa, como lo explicitaron enfoques sociales de los años setenta, acerca de cuáles deben ser consideradas condiciones materiales dignas y al servicio de una "buena vida» pero que sean real alternativa a una visión miserabilista - a veces expresadas en líneas de la pobreza utilizadas para medir avances de los gobiernos- o a otra de un proyecto de consumo insaciable al que se transfieren otros vacíos sociales (González, 200I). Es decir, en que el crecimiento no es considerado un fin, sino un medio, si necesario, para ciertos objetivos socioeconómicos ubicados en el orden de los fines. Aparece justificado sostener, con la historia recien- 
te detrás, que un crecimiento concebido sin pensar si ello fortalece o debilita los lazos humanos, la «convivialidad» como diría Iván Ilich, puede generar sacrificios humanos que terminan justificando más crecimiento del producto como compensaciones o «remedios» a los «males» que genera, pero que no añaden nada al bienestar (Baudrillard, I974). En esa perspectiva, el enfoque del «desarrollo humano» puede ser destacado en tanto propone la finalidad de ampliación del arco de libertad del sujeto para usar sus capacidades. Sin embargo, si el desarrollo de la ciencia, tecnología, producción y productividad no parecen ser una respuesta autosuficiente como en las primeras etapas del desarrollismo tampoco nos podemos situar en su negación total sin reconocer en ello un campo de y para la inventiva humana y la superación de situaciones que son social y humanamente penosas.

La discusión sobre niveles aceptables de consumo tiene una relación con otra materia que ha estado, de manera explícita o implícita, transversalmente presente en los enfoques de desarrollo: la distribución de ingresos, consumo y riqueza. La industrialización supuso que tenía altas capacidades inclusivas; el evolucionismo etapista o el dualismo supusieron períodos de acumulación dura, un "período sacrificial» que daría paso a un acceso generalizado al consumo; las visiones keynesianas presentes en algunos enfoques, como en el estructuralismo latinoamericano, supusieron una correlación positiva y necesaria entre crecimiento y mejoramiento de la distribución, al generar ésta aumento de la demanda y posibilitar economías de escala en la producción. A la vez, siempre han existido enfoques del liberalismo ortodoxo o neoliberalismo actual que han enfatizado la oposición a las políticas de distribución, bajo la acusación de populismo, y entendidas como directo desincentivo a la inversión privada y, con ello, al crecimiento y al empleo.

En otro momento, S. Kuznets planteó que el crecimiento tenía una primera fase de acentuación de la desigualdad de los ingresos y luego otra con tendencia a la una mayor igualación. Sin embargo, esto último parece ocurrir no como una tendencia natural o espontánea, sino producto de cambios institucionales que resultan de determinadas fuerzas sociales que logran influir en la construcción de aquéllas. Es decir, ciclos de expansión económica pueden implicar aumento o disminución de desigualdades según sea la institucionalidad en que esté enmarcada esa expansión. Fue esa constatación la que llevó, aunque sin ponerlo en cuestión, a relativizar al solo crecimiento como índice de desarrollo, en algunos enfoques. La idea de primero producir para luego distribuir olvida que ese proceso genera las condiciones para reproducir la desigualdad y expre- 
sa los intereses de quienes son favorecidos, generando sociedades articuladas en la asimetría y conectadas en la desigualdad socioeconómica; aumentando los miedos, las inseguridades y los recursos familiares y sociales asignados para la represión de una serie de consecuencias de aquello. Pero distribuir teniendo sólo como finalidad sustentar el crecimiento y el empleo al aumentar la demanda agregada — perspectiva keynesiana retomada por críticos al liberalismo actual frente a la recurrencia de las crisis - tampoco parece suficiente frente a las señaladas externalidades negativas de dicho crecimiento y a los límites actuales de un «crecimiento verde». Tampoco la distribución más justa puede sustentarse exclusivamente en el miedo a las inestabilidades políticas a las que la desigualdad puede conducir. Es necesario afirmar un marco normativo, que debe estar respaldado política y culturalmente, que haga de la justicia distributiva un valor social dominante (González, 2000).

Otro eje que puede ser detectado en una mirada retrospectiva y transversal es sobre los sujetos constructores del desarrollo. Los empresarios han sido destacados por el liberalismo como los sujetos del desarrollo en la medida que les sea brindado el espacio del mercado libre y sin fronteras nacionales, de acuerdo a su variante más radical actual. Ese comportamiento de homus economicus empresarial se planteó, además, como universal, aún presente en campesinos pobres de África que reaccionaban de esa misma forma ante el estímulo de los precios (Bustelo, I997). Los enfoques de sustitución de exportaciones, en sus lecturas más objetivas, realzaron la fuerte coalición entre Estado y grupos empresariales en la dirección de la economía, mixtura también presente en las propuestas del estructuralismo cepaliano. En general, el desarrollismo considerará siempre al Estado en un rol propulsor y acompañante más o menos imprescindible de la modernización económica. A veces para cubrir la falta de un empresariado, complementarlo, a veces buscando asegurar determinadas orientaciones del crecimiento económico para que fuese desarrollo, o sencillamente para encabezar el desarrollo productivo, como en el socialismo. Sumados esos Estados a las entidades internacionales de cooperación se constituiría una institucionalidad como agente o sujeto impulsor de estrategias y proyectos de desarrollo para «sacar» a las poblaciones del subdesarrollo.

Es esa perspectiva la que es puesta en cuestión por enfoques - como el desarrollo local o etnodesarrollo- que hacen ver que con aquello se transforma a la población en la beneficiaria de las acciones de otros agentes que serían los sujetos protagonistas del desarrollo, es decir, la primera resulta concebida como objeto del desarrollo, cuando sólo ella podría ser el sujeto de su propio 
desarrollo. Ello estuvo también ideológicamente presente en el enfoque socialista de una primera época, con relación a la participación de los trabajadores y estructuras de base en la gestión de la economía o en ciertas variantes más autogestionarias que lo acompañaron. Dicha perspectiva conduce a reforzar la idea de no separar «sujetos» y «objetos» del desarrollo y de recoger tradiciones «antitecnocráticas», discusión también presente en aquellos procesos socialistas en los debates acerca de la burocratización y centralización del poder. El desarrollo debe articularse con procesos democráticos que permitan su gestación por la sociedad. Sin embargo, ello no puede ser planteado como algo idílico desconociendo, por un lado, la complejidad social y la necesidad del saber y, por otro, las relaciones de poder que están presentes también en aquella. La realidad socioeconómica e institucional es generada por agentes que incluyen relaciones de poder y jerarquías cuya democratización enfrenta múltiples barreras.

Dentro de esa consideración anterior debe discutirse la cuestión del grado de «constructivismo» de la economía desde el sistema sociopolítico, con sus dimensiones tecnoprofesionales y político-administrativas y el rol del mercado y las iniciativas privadas. Las experiencias socialistas y asiáticas muestran el carácter verticalista y autoritario que puede tomar la relación del Estado con la sociedad, pero el neoliberalismo reciente muestra a su vez cómo el peso de los grandes agentes privados en el mercado puede hacer bastante formal los sistemas políticos democráticos. Ciertas vertientes del desarrollismo inicial concedieron una racionalidad suprema a la política tecnificada y al Estado versus las fuerzas espontáneas del mercado y la sociedad. El liberalismo radical concede la virtud de la racionalidad al mecanismo mercantil y atribuye la irracionalidad a la política y el Estado a través de calificativos como populismo, «precios políticos» o apropiación y redistribuidor de rentas, fundamentando altos grados de mercantilización de la sociedad y un desmontaje del Estado de Bienestar y de la economía no mercantil.

Todo esto refiere a cuál es la capacidad de la sociedad y sus sistemas de gobernanza de orientar la dinámica económica y, en el contexto actual, al control de una que está intensamente organizada desde la lógica de la acumulación del capital. En la medida que no hacemos asimilable al desarrollo con esa lógica, y guardamos para éste una definición centrada en el mejoramiento de la situación individual y colectiva, la regulación de dicha lógica aparece una condición del desarrollo. En esa perspectiva cobra valor la afirmación de la importancia de asegurar la construcción de «territorios de vida» organiza- 
dos en función de su calidad y no, exclusivamente, de la capacidad competitiva global de cada uno de ellos. Esto, como se planteó anteriormente, plantea la cuestión de las escalas de gobierno de la economía que abren a la discusión sobre la jerarquía de lo local y de lo global como niveles y escalas de gestión de la sociedad.

Estas consideraciones son suficientes para justificar que el desarrollo reclama miradas holísticas y una perspectiva histórica que aprehenda la complejidad de un proceso tal. Tanto en la dimensión «positiva» como en la «normativa» del desarrollo, los análisis de los procesos históricos y de las estructuras que se van formando como la imaginación de órdenes mejores que expresen deseos de mejor vivir, supone la confluencia de saber mirar las dimensiones amplias que marcan la vida social. En todo caso, a diferencia de otras «ramas» de la economía, la economía del desarrollo ha establecido conexiones permanentes con otras disciplinas de las ciencias sociales. Al respecto, cuando A. Lewis señalaba que la clave para entender la modernidad económica era explicar por qué una sociedad pasaba a ahorrar e invertir un porcentaje significativo de su producción e ingresos como condición permanente, concluía que ello era algo que debían responderse desde el conjunto de las ciencias sociales. Es decir, los teóricos del desarrollo en general han tenido claro la multiplicidad de factores y dimensiones comprendidas en él. La limitación estaba en cierta precariedad para entenderlos más profundamente, en verlos desde la pura funcionalidad al crecimiento, o en establecer dicotomías simples entre cultura moderna y cultura tradicional, etcétera.

La necesidad de considerar esas dimensiones amplias supone una aproximación desde una «socioeconomía política» que ponga en intersección plena a la economía con las otras ciencias sociales para aproximarse a los mundos concretos. Estos, además, son complejos, pues parecieran componerse de deseos de modernidad incumplida, de nuevos problemas emergidos con su avance y de búsquedas de condiciones posmodernas.

\section{Referencias}

Almond, Gabriel (1960). The politics of the developing areas. Princeton: Princeton University Press.

Amin, Samir (I993). «Nacionalismo». En J. Eatwell, M. Milgane y P. Newman (compiladores), Desarrollo económico. Barcelona: Icaria. 
Apostel, Leo (2001). Population, développement, environnement: pour des regards interdisciplinaires. Lovaina: Academia Bruylant, L'Harmattan.

Baldwin, Robert (1967). Desarrollo económico: un análisis introductorio. Buenos Aires: Amorrortu.

Baran, Paul (I97I). La economía política del crecimiento. La Habana: Editorial Ciencias SocialesBaudrillard, Jean (I974). La sociedad del consumo: sus mitos, sus estructuras. México: Siglo XXI.

Blaug, Mark (200I). Teoría económica en retrospección. Buenos Aires: Fondo de Cultura Económica.

Bonfil, Guillermo (1982). América Latina: etnodesarrollo y etnocidio. México: Facultad Latinoamericana de Ciencias Sociales (Flacso).

Bustelo, Pablo (1997). Teorías contemporáneas del desarrollo económico. Madrid: Síntesis.

Centre Tricontinental (200I). Socialisme et marché: Chine, Vietnam, Cuba. Lovaina: L'Harmattan.

Chenery, Hollis y otros (I974). Redistribution with Growth. Cambridge: Oxford University Press.

Dag Hammarskjöld (I975). «What now. Another Development. Dag Hammarskjöld Report». Development Dialogue.

De MatTos, Carlos (1984). Paradigmas, modelos y estrategias en la práctica latinoamericana de planificación regional. Bogota: ILPES, Bogotá.

Dickson, David (I980). Tecnología alternativa. Madrid: H. Blune.

Dos Santos, Theotonio (I972). Dependencia y cambio social. Santiago: Centro de Estudios Sociales (CESO).

EMMERIJ, Louis (I998). «Teoría y práctica del desarrollo: ensayo introductorio y conclusiones de política». En L. Emeerij (editor), Teorías del desarrollo a principios del siglo XXI. Banco Interamericano de Desarrollo.

FAnjzilber, Fernando (I990). «Industrialización en América Latina: de la caja negra al casillero vacío». Cuadernos de la Cepal núm. 60. Santiago.

Furtado, Celso (1970). Theoríe du developpement économique. París: PUF.

García de Fanelli, Ana (1986). «Talcott Parsons y la teoría del cambio social». Buenos Aires: Instituto de Desarrollo Económico y Social.

GonzÁlez, Raúl (I995). Espacio local, sociedad y desarrollo: razones de su valorización. Santiago: Universidad Academia de Humanismo Cristiano y Programa de Economía del Trabajo.

-. (2000): «La desigualdad: ¿vía para superar la pobreza?». Debates Económico Sociales núm. I. Programa de Economía del Trabajo. Santiago. 
-. (200I): «El consumo: más allá de lo privado, más acá de la condena». Revista de Economía y Trabajo, I I. Programa de Economía del Trabajo. Harrod, Roy. (I948): Towards a Dynamic Economics. Londres: Macmillan. Hinkelammert, Franz y H. Mora (200I). Coordinación social del trabajo, mercado y reproducción de la vida humana. Costa Rica: Departamento Ecuménico de Investigaciones.

Hirschman, Albert (I96I): «La estrategia del desarrollo económico». Fondo de Cultura Económica. México.

Jones, Hywell (1988). Introducción a las teorías modernas del crecimiento económico. Barcelona: Antoni Bosch.

Kanbur, Ravi y J. McIntosch (I993). «Economías duales». En J. Eatwell, M. Milgane y P. Newman (compiladores), Desarrollo económico Barcelona: Icaria.

KARDELJ, Edvard (I976). Les contradictions de la propriété sociale dans le systéme socialiste. París: Anthropos.

Kuklinski, Antoni (1985). «Desarrollo polarizado y políticas regionales. En Homenaje a Jaques Boudeville. México: Fondo de Cultura Económica.

LANGe, Oskar (1965a). «Problemas de la construcción socialista». En Problemas de economía política del socialismo. México: Fondo de Cultura Económica.

-. (1965b). Papel de la planeación en la economía socialista». En «Problemas de economía política del socialismo. México: Fondo de Cultura Económica.

-. (1965c). «Problemas de la construcción socialista». En Problemas de economía política del socialismo. México: Fondo de Cultura Económica

Lanzarotti, Mario (1990). La Corée du Sud, une sortie du sous-développement. París: IEDES.

Latouche, Serge (I988). "Contribution A l'histoire du concept de développement» . En C. Coquery-Vidrovitch, D. Hemery, J. Piel (eds), Pour une histoire u développement. (Etats, societés, développements). París: L'Harmattan.

-. (200I). La déraison de la raison économique. París: Albin Michel.

LAVILle, Jean Louis y Jordi García (2009). Crisis capitalista y economía solidaria. Barcelona: Icaria y Antrazyt.

Le Goff, Jaques (2005). Pensar la historia: modernidad, presente y progreso. Madrid: Paidós.

Leibenstein, Harvey (I957). «The theory of underemployment in backward economies». Journal of Political Economy, 65.

LEWIs, Arthur (1964). Teoría del desarrollo económico. México. 
L'Heriteau, M. F. (1986). Le Fond Monetaire International et les pays du Tiers Monde. París: Presses Universitaires du France.

Max Neef, Manfred (1985). El desarrollo a escala humana. Santiago: Cepaur y Fundación Dag Hammarskjöld.

Meadows, Donella y otros (1972). Los limites al crecimiento. Cambridge: Instituto Tecnológico de Massachusetts.

Myrdal, Gunnar (I959). Teoría económica y regiones subdesarrolladas. México: Fondo de Cultura Económica.

MARINI, Ruy Mauro (I974). Subdesarrollo y revolución. México: Siglo XXI.

Nurkse, Ragnar (1973). Problemas de formación de capital en países insuficientemente desarrollados. México: Fondo de Cultura Económica.

Peemans, J. Philippe (2002). «Le développement des peuples face à la modernization du monde». (Les theories du développement face aux histoires du développement «reel» dans la seconde moitié du XXème siècle). Lovaina: Academia Bruylant, L'Harmattan.

Perroux, Francois (1958). La coexistence pacifique. París: Presses Iniversitaires de France.

Polet, Francois (2008). L'Alter-Mondialisme. Bruselas: Centro Tricontinental.

Prebisch, Raúl (I95I). Problemas teóricos y prácticos del crecimiento económico. Santiago: Cepal.

-. (1963): Hacia una dinámica del desarrollo latinoamericano. México: Fondo de Cultura Económico.

Portes, Alejandro y William Haller (2004): La economía informal. Santiago: Cepal. División de Desarrollo Social.

Preston, Paul (I999). Una introduccion a la teoría del desarrollo. México: Siglo XXI.

Ranis, Gustav (I993). «Economías con excedente de mano de obra». En J. Eatwell, M. Milgane y P. Newman (compiladores), Desarrollo económico. Barcelona: Icaria

Rodríguez, Óscar (I980). La teoría del subdesarrollo de la Cepal. México: Siglo XXI.

RoDrik, Dany (I999). The new global economy and the developing countries: making openness work. Washington: Overseas Development Council.

Rosentein-Rodan, Paul (I962). "Notes on the theory of the big push». En H. S. Ellis (comp.), Economic development for Latin America. Londres: Macmillan. 
Rostow, Walt (1963). Las etapas del crecimiento económico. México: Fondo de Cultura Económica.

RutKowski, Jerzy (I965). "Algunos problemas de la industrialización socialista». En Problemas de economía política del socialismo. México: Fondo de Cultura Económica.

SEN, Amartya (2004). "Capital humano y capacidad humana». Cuadernos de economía. Foro de Economía Política-Teoría económica. Disponible en $<$ www.red-vertice.com/fep $>$.

Schumacher, Fritz (1987). Lo pequeño es hermoso. Madrid: Blume.

Sunkel, Osvaldo (comp.) (I99I). El desarrollo desde dentro: un enfoque neoestructuralista para América Latina. México: Cepal y Fondo de Cultura Económica.

VerHAEgen, Etienne (I998). «Le développement durable; entre science et politique». En M. Loriaux (editor), Populations et développement: une aproche globale et systémique. Lovaina: Academia Bruylant, L'Harmattan.

Wade, Robert (1999). El mercado dirigido. México: Fondo de Cultura Económica.

Wallerstein, Inmanuel (I984). El moderno sistema mundial. Madrid: Siglo XXI.

\section{Sobre al autor}

Raúl González Meyer es académico de la Universidad Academia de $\mathrm{Hu}$ manismo Cristiano. Economista Universidad de Chile. Magíster en Desarrollo Urbano Universidad Católica. Magíster en Desarrollo y Doctor en Ciencias Sociales (Desarrollo, Población y Medio Ambiente) por la Universidad Católica de Lovaina. Su correo electrónico es <rgonzalezm@docentes.academia.cl>. 